Check for updates

Cite this: RSC Adv., 2018, 8, 27546

\title{
Reduction-responsive diblock copolymer-modified gold nanorods for enhanced cellular uptake $\uparrow$
}

\author{
Yixia Li, ${ }^{a}$ Jianhao Si, ${ }^{a}$ Haiyan Fan, ${ }^{a}$ Jinxian Yang ${ }^{a}$ and Xiaodong Ye (D) *ab
}

Reduction-responsive polymer micelles are highly promising drug carriers with better tumor therapeutic effect, which can be achieved by controlled drug release under stimulation. Gold nanorods (AuNRs) have attracted considerable attention due to their unique optical and electronic properties when used for biomedical applications. Herein, the lipoic-acid-functionalized reduction-responsive amphiphilic copolymer poly $\left(\varepsilon^{-}\right.$ caprolactone)- $b$-poly[(oligoethylene glycol) acrylate] (LA-PCL-SS-POEGA) with a disulfide group between the two blocks was prepared to modify AuNRs via Au-S bonds. The size and morphology of AuNRs@LAPCL-SS-POEGA were measured by dynamic laser light scattering (DLS) and transmission electron microscopy (TEM) methods. The stabilities of AuNRs(ALA-PCL-SS-POEGA in different types of media were studied by UV/vis spectroscopy and DLS techniques. The results show that AuNRs@LA-PCL-SS-POEGA gradually aggregate in a concentrated salt solution containing $150 \mathrm{mM}$ dithiothreitol (DTT), but exhibit high stability in a non-reducing environment. Near infrared (NIR)-induced heating of AuNRs@LA-PCL-SS-POEGA was investigated in an aqueous solution under NIR laser irradiation $(808 \mathrm{~nm})$, revealing that AuNRs@LA-PCLR-POEGA maintain excellent photothermal conversion efficiency after modification. When compared with non-reduction responsive AuNRs@LA-PCL-CC-POEGA, the in vitro internalization of AuNRs@LA-PCL-SSPOEGA demonstrates that the reduction-responsive polymer could enhance the cellular uptake of nanoparticles measured by inductively coupled plasma mass spectrometry (ICP-MS) and TEM.

Received 25th April 2018 Accepted 14th July 2018

DOI: $10.1039 / \mathrm{c} 8 \mathrm{ra03545h}$

rsc.li/rsc-advances tumor sites. ${ }^{13-18}$ For example, Zhong et al. have conducted a series of studies on the use of reduction-responsive polymers as anticancer drug carriers including disulfide-linked dextran-b-poly( $\varepsilon$ caprolactone) (Dex-SS-PCL), poly(ethylene glycol)-b-poly( $\varepsilon$-caprolactone) (PEG-SS-PCL), and poly(ethyleneglycol)-b-poly(2,4,6trimethoxybenzylidene-pentaerythritol carbonate) (PEG-SSPTMBPEC). They stated that the reduction-responsive micelles efficiently delivered and rapidly released doxorubicin (DOX) into cancer cells, resulting in better anti-tumor activity when compared with conventional micelles. ${ }^{19-21}$

Moreover, reduction-responsive micelles can be used in combination with other materials to obtain more therapeutic possibilities..$^{22,23}$ Recently, some works about integrating photothermal materials such as gold nanorods (AuNRs) into nanomedicine carriers have attracted widespread attention because of the tunable surface plasmon and photothermal effects of AuNRs. For example, Chen and coworkers have successfully prepared a single nanocomposite by sheltering AuNRs@SiO ${ }_{2}$ with a thermo-responsive polymer shell poly $(N$ isopropylacrylamide- $c o$-acrylic acid) (PNIPAM-co-PAA), which could increase the blood circulation time and inhibit tumor growth by water bath heating and NIR laser irradiation. ${ }^{24}$

In addition, they studied the influence of aspect ratio and surface chemistry of AuNRs on internalization and cytotoxicity. They stated that both aspect ratio and surface chemistry affected
${ }^{a}$ Hefei National Laboratory for Physical Sciences at the Microscale, Department of Chemical Physics, University of Science and Technology of China, Hefei, Anhui 230026, China.E-mail: xdye@ustc.edu.cn

${ }^{b}$ CAS Key Laboratory of Soft Matter Chemistry, University of Science and Technology of China, Hefei, Anhui 230026, China

$\dagger$ Electronic supplementary information (ESI) available. See DOI: 10.1039/c8ra03545h 
the cellular uptake, while the cytotoxicity was highly dependent on the surface chemistry. ${ }^{25}$ Besides, some other works about the toxicology of Au nanoparticles, including AuNRs, have been reported. ${ }^{26-35}$ Wang and coworkers systematically investigated the cellular uptake behavior and cytotoxicity of AuNRs with various surface coatings, including organic and inorganic materials. Their results indicated that AuNRs with organic polymer surface coatings showed lower cellular uptake and photothermal effects in U-87 MG cells. ${ }^{26}$ Additionally, Zhong et al. prepared AuNRcored biodegradable poly(ethylene glycol)- $b$-poly( $\varepsilon$-caprolactone) block copolymer micelles for drug delivery. Their results have shown that the micelles efficiently delivered and released DOX into the nuclei of multidrug-resistant (MDR) cancer cells, resulting in high efficiency reversal of drug resistance.$^{36}$ However, Duguet et al. have mentioned that AuNRs coated with poly( $(\varepsilon-$ caprolactone)- $b$-poly(ethylene glycol) had a relatively low cellular uptake, with an averaged uptake of $1250 \pm$ (110) particles per melanoma MEL-5 cells after incubation at $50 \mu \mathrm{g} \mathrm{mL}{ }^{-1}$ for $12 \mathrm{~h}^{.37}$ Thus, it would be interesting to investigate if the cellular uptake of AuNRs can be improved by modification with reductionsensitive amphiphilic polymers.

In this study, reduction-responsive amphiphilic copolymer poly( $\varepsilon$-caprolactone)- $b$-poly[(oligoethylene glycol) acrylate] (LAPCL-SS-POEGA) with a disulfide group and a control copolymer without a disulfide group were first prepared, as shown in Scheme 1. Due to the approved use of PCL in drug delivery by US Food and Drug Administration (FDA) and good biocompatibility of POEGA, we chose PCL as the hydrophobic block and POEGA as the hydrophilic segment. ${ }^{38,39} \mathrm{CTAB}$ on the surface of AuNRs was replaced with reduction-sensitive amphiphilic copolymer or reduction-nonsensitive copolymer to reduce cytotoxicity. The stabilities of AuNRs coated with an amphiphilic polymer in different environments, including the reducing environment, were investigated by UV/vis spectrophotometer and DLS. Furthermore, the effect of disulfidelinked copolymer on the thermal property, cytotoxicity, and cellular uptake of AuNRs@LA-PCL-SS-POEGA was systematically investigated.

\section{Experimental section}

\section{Materials and methods}

Oligo(ethylene glycol) methyl ether acrylate (OEGA, $M_{\mathrm{n}}=480 \mathrm{~g}$ $\mathrm{mol}^{-1}$, Sigma-Aldrich) was passed through a short column of alkaline alumina to remove the inhibitor. $\varepsilon$-Caprolactone (CL, Aladdin, 99\%) was distilled under reduced pressure after drying over calcium hydride $\left(\mathrm{CaH}_{2}\right)$. 2-Hydroxyethyl disulfide (Aldrich, 90\%), 2-bromo-2-methyl-propionyl bromide (Energy Chemical, 98\%), $N, N, N^{\prime}, N^{\prime}, N^{\prime \prime}$-pentamethyldiethylenetriamine (PMDETA, Sigma-Aldrich, 99\%), stannous octoate $\left(\mathrm{Sn}(\mathrm{EH})_{2}\right.$, SigmaAldrich, 95\%), lipoic acid (LA, Damas-Beta, 99\%), 4-dimethyl aminopyridine (DMAP, Aladdin, 99\%), 1-ethyl-3-(3dimethylaminopropyl) carbodiimide hydrochloride (EDC, Aladdin, 98\%), cetyltrimethylammonium bromide (CTAB, Sinopharm, 99\%), hydrochloric acid (HCl, Sinopharm), concentrated nitric acid $\left(\mathrm{HNO}_{3}\right.$, Sinopharm), sodium borohydride $\left(\mathrm{NaBH}_{4}\right.$, Sinopharm, 98\%), silver nitrate $\left(\mathrm{AgNO}_{3}\right.$, Sinopharm, 99\%), L-ascorbic acid (AA, Sinopharm, 99\%), hydrogen tetrachloroauric acid $\left(\mathrm{HAuCl}_{4} \cdot 3 \mathrm{H}_{2} \mathrm{O}\right.$, Energy Chemical, 99.99\%), and dithiothreitol (DTT, Aladdin, 99\%) were used without any treatment. Dimethyl sulfoxide (DMSO, Sinopharm, 97\%) and dimethylformamide (DMF, Sinopharm, 97\%) were dried over anhydrous magnesium sulfate and then purified by distillation under reduced pressure. Dichloromethane (DCM, Sinopharm, 97\%) and triethylamine (TEA, Sinopharm, 99\%) were distilled over $\mathrm{CaH}_{2}$. Tetrahydrofuran (THF, Sinopharm, 97\%) and toluene (Sinopharm, 97\%) were distilled after refluxing over metal sodium for $24 \mathrm{~h}$.

\section{Preparation of the initiator $\mathrm{HO}-\mathrm{SS}-\mathrm{Br}$}

The small molecule initiator was synthesized according to previous works with certain modifications as follows. ${ }^{\mathbf{4 0 , 4 1}} 2$ Hydroxyethyl disulfide $(5.1 \mathrm{~g}, 33.1 \mathrm{mmol})$ and TEA $(4.63 \mathrm{~mL}$, $33.3 \mathrm{mmol}$ ) were dissolved in $80 \mathrm{~mL}$ purified THF and DCM (30/ $50, \mathrm{v} / \mathrm{v})$ at $25{ }^{\circ} \mathrm{C}$. Under a nitrogen flow, $\alpha$-bromoisobutyryl bromide ( $4.12 \mathrm{~mL}, 33.3 \mathrm{mmol}$ ) was dissolved in purified DCM $(10 \mathrm{~mL})$ and was added dropwise into the reaction mixture at
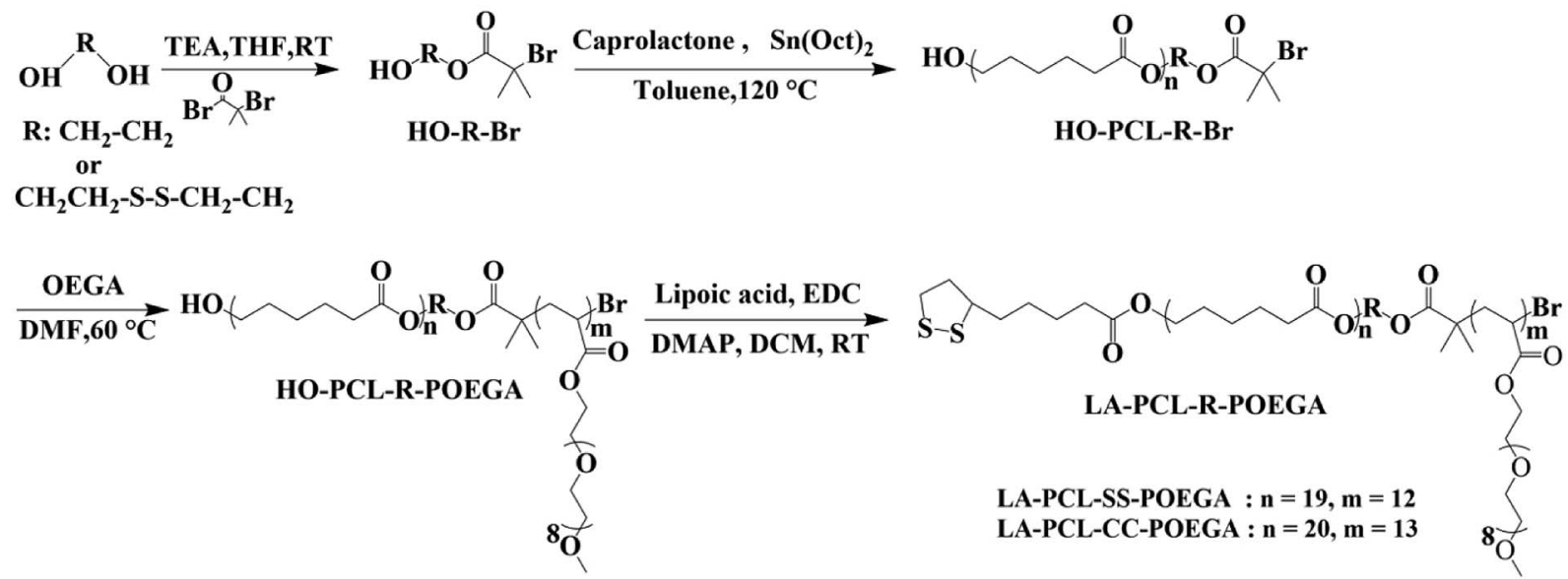

Scheme 1 Synthetic routes for LA-PCL-SS-POEGA and LA-PCL-CC-POEGA. 
$0{ }^{\circ} \mathrm{C}$ within $30 \mathrm{~min}$. Then, the mixture was stirred for $10 \mathrm{~h}$ at room temperature. After that, the solvent was removed by rotary evaporation under reduced pressure, and the mixture was redissolved in THF and filtered to remove the salts. The crude product was purified by column chromatography after removing THF (eluent: $n$-hexane/ethyl acetate ratio of $10: 1$ ) to give a pale-yellow clear oil (HO-SS-Br, $4.9 \mathrm{~g}$ ) in a $49 \%$ yield.

\section{Preparation of HO-SS-PCL-Br}

HO-PCL-SS-Br was prepared by ring-opening polymerization (ROP) using $\mathrm{HO}-\mathrm{SS}-\mathrm{Br}$ as the initiator and $\mathrm{Sn}(\mathrm{EH})_{2}$ as the catalyst. $^{42,43} \mathrm{HO}-\mathrm{SS}-\mathrm{Br}(0.44 \mathrm{~g}, 1.45 \mathrm{mmol}), \mathrm{Sn}(\mathrm{EH})_{2}(0.118 \mathrm{~g}$, $0.29 \mathrm{mmol})$, CL (3.00 g, $26.30 \mathrm{mmol}$ ), and anhydrous toluene (30 $\mathrm{mL}$ ) were added into a three-necked, round-bottomed flask. The reaction mixture was refluxed for $6 \mathrm{~h}$ at $120^{\circ} \mathrm{C}$ under a nitrogen atmosphere. Then, the mixture was redissolved in THF after toluene was removed by distilling under reduced pressure. The polymers dissolved in THF were precipitated into an excess of the mixture of cold methanol/water $(2 / 1, \mathrm{v} / \mathrm{v})$. The polymer HOPCL-SS-Br $\left(M_{\mathrm{n}}=2.2 \times 10^{3} \mathrm{~g} \mathrm{~mol}^{-1}, 2.8 \mathrm{~g}\right.$, yield: 93\%) was collected by filtration and dried under a vacuum for $24 \mathrm{~h}$.

\section{Preparation of HO-PCL-SS-POEGA}

The amphiphilic polymers were synthesized by atom transfer radical polymerization (ATRP) as follows. Macroinitiator HOSS-PCL-Br (0.5 g, $0.2 \mathrm{mmol})$, monomer OEGA (2.4 g, $5 \mathrm{mmol})$, ligand PMDETA (34.66 mg, $0.2 \mathrm{mmol}$ ), and $3 \mathrm{~mL}$ of anhydrous DMF were added into a $10 \mathrm{~mL}$ glass tube with a magnetic stirrer. Catalyst $\mathrm{CuBr}(28.8 \mathrm{mg}, 0.2 \mathrm{mmol})$ was added into the tube with a hot funnel after degassing three times by freeze-pump-thaw cycles; subsequently, the tube was sealed under a vacuum. After that, the tube was placed in a $60{ }^{\circ} \mathrm{C}$ oil bath and stirred for $3.5 \mathrm{~h}$. Then, the reaction was rapidly terminated by freezing with liquid nitrogen. To remove the copper salts, the mixture was diluted with THF and passed through a neutral alumina column using THF as the eluent. The mixture was concentrated by rotary evaporation and then precipitated into an excess amount of cold diethyl ether/ $n$-hexane $(1 / 2, \mathrm{v} / \mathrm{v})$. A sticky solid of HOPCL-SS-POEGA was collected by filtration and dried under a vacuum for $24 \mathrm{~h}$. HO-PCL-SS-POEGA was obtained as a sticky white solid (1.2 g, yield: $80 \%$ ) after the reaction of ATRP.

\section{Preparation of LA-PCL-SS-POEGA}

The hydroxyl groups at the end of the PCL chains were modified with LA by esterification modification. HO-PCL-SS-POEGA $(0.8 \mathrm{~g}, 0.1 \mathrm{mmol})$ was dissolved in $20 \mathrm{~mL}$ of purified DCM and then LA (0.113 g, $0.5 \mathrm{mmol})$, DMAP ( $5.7 \mathrm{mg}, 0.044 \mathrm{mmol})$, and TEA $(15 \mu \mathrm{L}, 0.1 \mathrm{mmol})$ were added step by step. EDC $(0.1 \mathrm{~g}, 0.5$ $\mathrm{mmol}$ ) was added into the reaction mixture under a nitrogen atmosphere at $0{ }^{\circ} \mathrm{C}$. The reaction was stopped after stirring for $24 \mathrm{~h}$ at room temperature. Thereafter, DCM was removed by a rotary evaporator, and the residues were dissolved in THF; the salt precipitate was then removed by centrifugation. Finally, the supernatant was precipitated into an excess amount of cold diethyl ether/ $n$-hexane $(1 / 2, \mathrm{v} / \mathrm{v})$. LA-PCL-SS-POEGA (0.6 g, yield: $79 \%$ ) was obtained as a pale yellow sticky solid by modifying the hydroxyl groups with LA and drying under a vacuum at room temperature for $24 \mathrm{~h}$. The reductionnonresponsive copolymer LA-PCL-CC-POEGA was prepared by a similar procedure, as shown in Scheme 1 .

\section{Preparation of AuNRs by seed-growth methods}

AuNRs were synthesized based on a seed-growth procedure with some modification. ${ }^{44}$ Au seeds were prepared by adding $\mathrm{HAuCl}_{4} \cdot 3 \mathrm{H}_{2} \mathrm{O}(25 \mathrm{mM}, 0.1 \mathrm{~mL})$ into CTAB $(0.1 \mathrm{M}, 10 \mathrm{~mL})$ solution, followed by thorough mixing. Then, freshly prepared ice-cold $\mathrm{NaBH}_{4}(0.01 \mathrm{M}, 600 \mu \mathrm{L})$ was rapidly added under vigorous stirring, resulting in the formation of a brownishyellow solution. This seed solution was kept at $28{ }^{\circ} \mathrm{C}$ in a water bath for $2 \mathrm{~h}$. After that, the growth solution was prepared in a $100 \mathrm{~mL}$ conical flask as follows: $100 \mathrm{~mL}$ of CTAB (3.6445 g, $0.1 \mathrm{M}$ ) solution, $1.2 \mathrm{~mL}$ of $\mathrm{AgNO}_{3}(16.987 \mathrm{mg}, 10 \mathrm{mM}$ ) solution, $2 \mathrm{~mL}$ of aqueous $\mathrm{HAuCl}_{4} \cdot 3 \mathrm{H}_{2} \mathrm{O}(19.69 \mathrm{mg}, 25 \mathrm{mM})$, and a certain amount of $\mathrm{HCl}(1 \mathrm{M})$ solution were thoroughly mixed in a conical flask. Then, $0.7 \mathrm{~mL}$ solution of AA $(9.72 \mathrm{mg}$, $78.8 \mathrm{mM}$ ) was slowly added into the solution mentioned above under gentle stirring. Finally, the solution was left undisturbed at $28{ }^{\circ} \mathrm{C}$ overnight after $120 \mu \mathrm{L}$ seed solution was added. The AuNRs@CTAB were obtained after centrifuging at $8000 \mathrm{rpm}$ for $15 \mathrm{~min}$ and redispersed in deionized water.

\section{Preparation of AuNRs@LA-PCL-R-POEGA nanoparticles}

Typically, AuNRs@CTAB (0.25 mg) were diluted with water to $10 \mathrm{~mL}$ and centrifuged at $8000 \mathrm{rpm}$ for $15 \mathrm{~min}$, the supernatant was discarded, and the precipitate was redispersed in $2.5 \mathrm{~mL}$ of ultrapure water. Further, $5 \mathrm{mg}$ LA-PCL-SS-POEGA diblock copolymer was dissolved in $1 \mathrm{~mL}$ purified DMSO, and added dropwise into AuNRs (2.5 mL, $0.1 \mathrm{mg} \mathrm{mL}^{-1}$ ) solution using an injection pump at a speed of $1 \mathrm{~mL} \mathrm{~h}^{-1}$ under stirring. The mixture was kept at room temperature for $24 \mathrm{~h}$ and then centrifuged at $8000 \mathrm{rpm}$ for $15 \mathrm{~min}$ and washed with DMSO (2.5 $\mathrm{mL})$ and water $(2.5 \mathrm{~mL})$ to remove the excess polymers. In the end, the precipitate was redispersed in $2.5 \mathrm{~mL}$ of deionized water and dialyzed against $1 \mathrm{~L}$ deionized water in a dialysis bag (Green Bird; molecular weight cut-off (MWCO) $=3500 \mathrm{Da}$ ) for $24 \mathrm{~h}$. The water was changed every $6 \mathrm{~h}$ to remove the organic solvent.

\section{Characterization}

\section{${ }^{1} \mathrm{H}$ NMR}

The ${ }^{1} \mathrm{H}$ NMR spectra were conducted on a Bruker AV400 spectrometer using tetramethylsilane (TMS) as the internal reference. Each sample was dissolved in deuterated chloroform $\left(\mathrm{CDCl}_{3}, 0.6 \mathrm{~mL}\right)$ at a concentration of $\sim 20 \mathrm{mg} \mathrm{mL}^{-1}$.

\section{Gel permeation chromatography (GPC)}

The macromolecular weight information including numberaverage molar mass $\left(M_{\mathrm{n}}\right)$, weight-average molar mass $\left(M_{\mathrm{w}}\right)$, and dispersity $\left(M_{\mathrm{w}} / M_{\mathrm{n}}\right)$ of the polymers were measured at $35^{\circ} \mathrm{C}$ by a Waters 1515 GPC instrument equipped with three Waters Styragel columns (HR2, HR4, and HR6) and a refractive index 
detector (RI, Wyatt WREX-02). THF was used as the eluent at

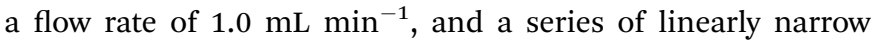
distribution of polystyrene with different molecular weights were used as the standard samples.

\section{Characterization of AuNRs@CTAB and AuNRs@LA-PCL-R- POEGA nanoparticles}

The absorption spectra of AuNRs@CTAB and the modified AuNRs@LA-PCL-R-POGEA nanoparticles were measured in the visible to near-infrared light region using a UV/vis spectrophotometer (UNICO2802PCS). The morphologies of AuNRs@CTAB and AuNRs@LA-PCL-R-POEGA nanoparticles were observed by a transmission electron microscope (TEM, Hitachi H-7650, $100 \mathrm{kV}$ ). The average hydrodynamic diameters and zeta potentials of micelles were measured at $25{ }^{\circ} \mathrm{C}$ on a Zetasizer Nano-ZS (Malvern Instruments) with a $633 \mathrm{~nm} \mathrm{He}$ Ne laser as the light source.

\section{Stability of AuNRs@LA-PCL-R-POEGA nanoparticles}

The stabilities of AuNRs@LA-PCL-R-POGEA were probed by a UV/vis spectrophotometer in different types of dispersion media, including PBS, $2 \mathrm{M} \mathrm{NaCl}$, and high concentration of salt solution containing DTT. The DTT competition test was also used to assess the stability of AuNRs@LA-PCL-R-POGEA, according to the ref. 45 and 46. Firstly, a certain amount of DTT $(23.13 \mathrm{mg})$ was added into a degassed solution of $\mathrm{NaCl}(100 \mu \mathrm{L}$, $4 \mathrm{M}$ ) in a quartz cuvette with a thread capsule and thoroughly mixed. After that, the whole solution was degassed with high purity of nitrogen for $1 \mathrm{~min}$ after a certain amount of AuNRs@LA-PCL-R-POEGA and water were added to make the longitudinal absorption band around $800 \mathrm{~nm}$ of $\sim 0.3-0.4$ under the concentration of DTT $\sim 150 \mathrm{mM}$ and $\mathrm{NaCl} \sim 400 \mathrm{mM}$. Then, a series of absorption spectra were measured at various time intervals to monitor the changes in the absorption peaks. In addition, we determined the average hydrodynamic diameters of the AuNRs@LA-PCL-R-POEGA at $37{ }^{\circ} \mathrm{C}$ over time by DLS, which were dispersed in the cell culture medium containing DMEM, 10\% FBS, 1\% sodium pyruvate, and 1\% penicillinstreptomycin.

\section{Photothermal heating experiments}

The aqueous solutions of AuNRs@CTAB and AuNRs@LA-PCLR-POEGA were diluted to $100 \mu \mathrm{g} \mathrm{mL}^{-1}(200 \mu \mathrm{L})$ and irradiated with an $808 \mathrm{~nm}$ NIR laser (New Industries Optoelectronics, Changchun, China) for $10 \mathrm{~min}$ at a power density of $200 \mathrm{~mW}$ $\mathrm{cm}^{-2}$. The change in temperature was monitored by an IR camera (ICI7320, Infrared Camera Inc., Texas, USA) every $10 \mathrm{~s}$ and analyzed using IR Flash thermal imaging analysis software. Similarly, various concentrations $\left(100,50\right.$, and $\left.20 \mu \mathrm{g} \mathrm{mL}^{-1}\right)$ of AuNRs@LA-PCL-SS-POEGA in water were also irradiated with an $808 \mathrm{~nm}$ NIR laser at the same power density and detected under the same conditions. Deionized water was used as the control.

\section{Cytotoxicity tests}

The standard MTT assay was used to assess the cell viability under different conditions. Briefly, the Hela cells were seeded in a 96-well plate with a density of 5000 cells per well and cultivated in a $5 \% \mathrm{CO}_{2}$ atmosphere at $37{ }^{\circ} \mathrm{C}$ for $24 \mathrm{~h}$. Then, the medium was replaced with different concentrations of AuNRs@LA-PCL-R-POEGA dispersed in the medium containing DMEM, 10\% FBS, 1\% sodium pyruvate, and 1\% penicillinstreptomycin, and the cells were incubated for another $24 \mathrm{~h}$. Thereafter, the MTT solution $\left(120 \mu \mathrm{L}, 0.5 \mathrm{mg} \mathrm{mL}^{-1}\right)$ was added to each well after the medium containing nanoparticles was removed. After incubation for an additional $4 \mathrm{~h}$, the MTT solution was removed and $150 \mu \mathrm{L}$ of DMSO was added. The absorbance of solubilized formazan was measured after thoroughly mixing at $595 \mathrm{~nm}$ by a spectrophotometric plate reader (Bio-Rad iMark). The measurement for each treatment was repeated six times.

\section{Cell internalization of AuNRs@LA-PCL-R-POEGA}

A total of $1 \times 10^{5}$ Hela cells per well were plated in 24-well plates. After cultivating for $24 \mathrm{~h}$, the medium was replaced by AuNRs@LA-PCL-R-POEGA (400 $\left.\mu \mathrm{L}, 75 \mu \mathrm{g} \mathrm{mL}{ }^{-1}\right)$ dispersed in a culture medium and then placed in an incubator for $24 \mathrm{~h}$ or $36 \mathrm{~h}$. Thereafter, the cells were washed three times with PBS to remove the nanoparticles adsorbed on the cells surface and then detached with trypsin. After $5 \mathrm{~min}$, a DMEM medium (1 $\mathrm{mL}$ ) was added to homogeneously disperse the cells; the cells were then collected and the number of cells in the solution per well were counted. After that, the cells were collated by centrifugation at a speed of $1000 \mathrm{rpm}$ for $5 \mathrm{~min}$, and $\mathrm{HNO}_{3}(2 \mathrm{~mL})$ was added into the tube for pre-digestion overnight. After $12 \mathrm{~h}, \mathrm{HCl}$ $(6 \mathrm{~mL})$ was mixed with $\mathrm{HNO}_{3}$, and the mixture was boiled at $140{ }^{\circ} \mathrm{C}$ until the solution became colorless and clear; then, the residual solution was diluted with deionized water to $10 \mathrm{~mL}$. The concentration of $\mathrm{Au}$ ions of liquid $(10 \mathrm{~mL})$ was determined using an inductively coupled plasma mass spectrometer (ICPMS; Plasma Quad 3). The number of AuNRs per cell was calculated based on the mass of the individual AuNR and the number of cells. The measurement for each treatment was repeated in triplicate.

\section{TEM analysis for cellular uptake}

The morphology and location of AuNRs in fixed cells was obtained using a TEM (JEM-2100). Hela cells were incubated in $2 \mathrm{~mL}$ of medium (DMEM) at a density of $1.0 \times 10^{6}$ cells. After $24 \mathrm{~h}$, the medium was discarded and replaced with $2 \mathrm{~mL}$ of 75 $\mu \mathrm{g} \mathrm{mL}^{-1}$ AuNRs@LA-PCL-R-POEGA dispersed in a DMEM medium and then placed in an incubator for $36 \mathrm{~h}$. After removing the medium containing AuNRs@LA-PCL-R-POEGA, the cells were washed with PBS for three times and detached with trypsin; they were then collected by centrifugation at $1500 \mathrm{rpm}$ for $8 \mathrm{~min}$. After discarding the supernatant, the cells were fixed by $3 \%$ glutaraldehyde solution overnight; they were then embedded in resin, cut into ultrathin sections, and stained 
by osmic acids. Finally, the location and morphology of AuNRs in the cells were detected by TEM.

\section{Results and discussion}

\section{Synthesis of LA-PCL-R-POEGA copolymers}

As shown in Scheme 1, LA-PCL-R-POEGA was prepared by ROP and ATRP. First of all, the initiator HO-SS-Br was synthesized through an esterification reaction. The purity and structure of the initiator were confirmed by ${ }^{1} \mathrm{H}$ NMR (Fig. S1†). Secondly, we prepared HO-PCL-R-Br by ROP of $\varepsilon$-caprolactone using HO-R$\mathrm{Br}$ as the initiator and $\mathrm{Sn}(\mathrm{EH})_{2}$ as a catalyst in toluene. The degree of polymerization (DP) was measured by ${ }^{1} \mathrm{H}$ NMR (Fig. S2 $\dagger$ ). Fig. S2 $\uparrow$ shows that the protons at $-\mathrm{COO}-\mathrm{CH}_{2}-\mathrm{CH}_{2}-$ $\mathrm{SS}-\mathrm{CH}_{2}-\mathrm{CH}_{2}-\mathrm{OOC}$, -OOC- $\mathrm{CH}_{2}-\mathrm{CH}_{2}-\mathrm{CH}_{2}-\mathrm{CH}_{2}-\mathrm{CH}_{2} \mathrm{O}-$, - OOC$\mathrm{CH}_{2}-\mathrm{CH}_{2}-\mathrm{CH}_{2}-\mathrm{CH}_{2}-\mathrm{CH}_{2} \mathrm{O}-$, and $-\mathrm{OOC}-\mathrm{CH}_{2}-\mathrm{CH}_{2}-\mathrm{CH}_{2}-\mathrm{CH}_{2}-$ $\mathrm{CH}_{2} \mathrm{O}$ - on the carbon chain backbone of the PCL block are located at 2.87-2.98 ppm (f), 2.18-2.40 ppm (d), 4.01-4.10 ppm (a), and 1.50-1.72 ppm (b), respectively. According to the integral area ratio of the peak $\left(A_{\mathrm{d}} / A_{\mathrm{f}}, A_{\mathrm{a}} / A_{\mathrm{f}}\right.$, or $\left.A_{\mathrm{b}} / A_{\mathrm{f}}\right)$, the DP of PCL was calculated as 19 . Meanwhile, the end retention of the terminal bromine and hydroxyl in the polymer HO-PCL-R-Br are $\sim 99 \%$ according to the integral area ratio of the peak area $\left(A_{\mathrm{g}} / A_{\mathrm{f}}\right)$ and $\left(A_{\mathrm{a}^{\prime}} / A_{\mathrm{f}}\right)$.

In addition, we used HO-PCL-R-Br as the macroinitiator, $\mathrm{CuBr}$ as the catalyst, and PMEDTA as the ligand in DMF to obtain the copolymer HO-PCL-R-POEGA. Similarly, the DP of the hydrophilic segments was calculated as 12 according to the area ratio of the characteristic peaks in the ${ }^{1} \mathrm{H}$ NMR spectrum (Fig. S3 $\dagger$ ). According to the integral area ratio of the characteristic peaks of the protons at $-\mathrm{COO}-\mathrm{CH}_{2}-\mathrm{CH}_{2}-\mathrm{SS}-\mathrm{CH}_{2}-\mathrm{CH}_{2}-$ OOC, OOC- $\mathrm{CH}_{2}-\mathrm{CH}_{2}-\mathrm{CH}_{2}-\mathrm{CH}_{2}-\mathrm{CH}_{2} \mathrm{O}-,-\mathrm{COO}-\mathrm{CH}_{2}-\mathrm{CH}_{2}-\mathrm{O}-$ $\mathrm{CH}_{2}-$, and $-\mathrm{O}-\mathrm{CH}_{3}$ are located at $2.87-2.98$ ppm (f), 1.29$1.48 \mathrm{ppm}(\mathrm{c}), 4.10-4.28 \mathrm{ppm}(\mathrm{k})$, and 3.32-3.42 ppm (q), respectively; the DP of the hydrophilic segments was obtained as 12, as shown in Fig. S3†. It is difficult to calculate the degree of functionality of the hydroxyl group after ATRP due to the overlapping of the peaks. At the end, the final product was obtained by modifying the hydroxyl groups at the end of the PCL chains with LA. After precipitation for five times, we concluded that there was no change in the integral area of the characteristic peaks of LA before and after precipitation, indicating the complete removal of the free LA molecules. Moreover, the characteristic protons peaks of LA can be observed from Fig. 1, such as the peaks $(\mathrm{z}, \mathrm{v}, \mathrm{w}, \mathrm{y})$. The degree of functionality of LA is 99\% according to the integral area ratio of the peak area $\left(A_{\mathrm{z}} / A_{\mathrm{f}}\right)$. Fig. 1 shows the ${ }^{1} \mathrm{H}$ NMR spectrum of LA-PCL-SS-POEGA, and the integral area ratio of peak (z), peak (f), peak (c $+\mathrm{x})$, and peak (q) is almost $1.00 / 2.05 / 20.0 / 20$, which is consistent with the theoretical ratio. Therefore, $M_{\mathrm{n}}$ calculated from the ${ }^{1} \mathrm{H}$ NMR spectrum for the copolymer LA-PCL-SS-POEGA is approximately $8000 \mathrm{~g} \mathrm{~mol}^{-1}$. The GPC curves of the polymers shown in Fig. 2 reveal that the retention time of HO-PCL-SS-POEGA is obviously shorter than that of HO-PCL-SS-Br, which confirms the success of the ATRP process. The results involving the reduction-nonsensitive initiator and copolymers $\mathrm{HO}-\mathrm{CC}-\mathrm{Br}$, HO-PCL-CC-Br, HO-PCL-CC-POEGA, and LA-PCL-CC-

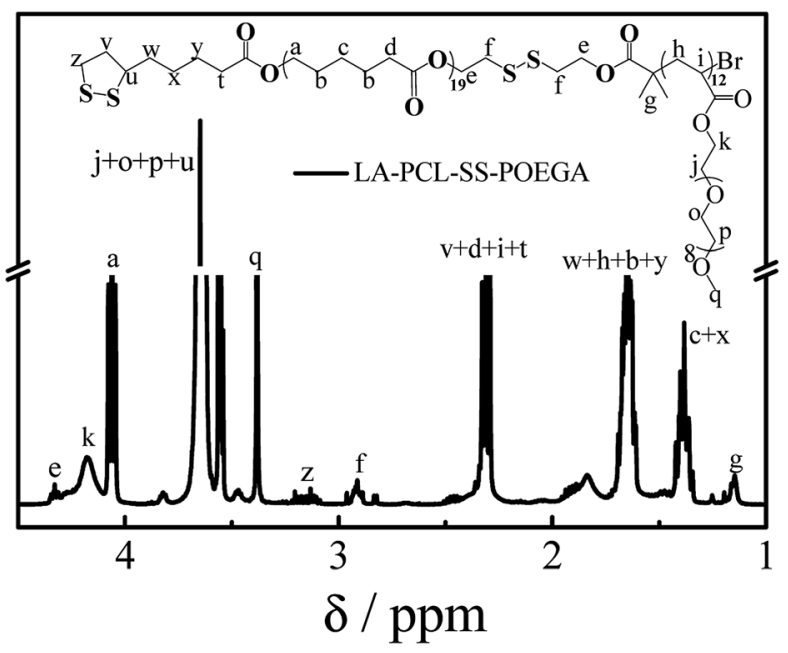

Fig. $1{ }^{1} \mathrm{H}$ NMR spectrum of disulfide-linked polymer LA-PCL-SSPOEGA measured in $\mathrm{CDCl}_{3}$ with TMS as an internal reference.

POEGA are shown from Fig. S4 to S8, respectively, in the ESI. $\dagger$ Moreover, $M_{\mathrm{n}}$ calculated from the ${ }^{1} \mathrm{H}$ NMR spectrum for the copolymer LA-PCL-CC-POEGA is approximately $8500 \mathrm{~g} \mathrm{~mol}^{-1}$.

\section{Preparation and characterization of AuNRs@CTAB and AuNRs@LA-PCL-R-POEGA nanoparticles}

A number of methods for synthesizing AuNRs have been reported, such as the template method, electrochemical method, and seed-growth method. ${ }^{\mathbf{4 4 , 4 7 , 4 8}}$ We synthesized AuNRs using the seed-growth method reported by El-Sayed et al. with some modifications. ${ }^{4,49}$ The TEM image illustrates that AuNRs are monodisperse in water with an average length of $60 \pm 8 \mathrm{~nm}$ and a width of $16 \pm 3 \mathrm{~nm}$. As shown in Fig. 3(c), the distribution of the relaxation time for AuNRs@CTAB exhibit two peaks, as measured by DLS: the first peak at $7-40 \mu \mathrm{s}$ is attributed to rotational diffusion and the other one with a longer relaxation time is

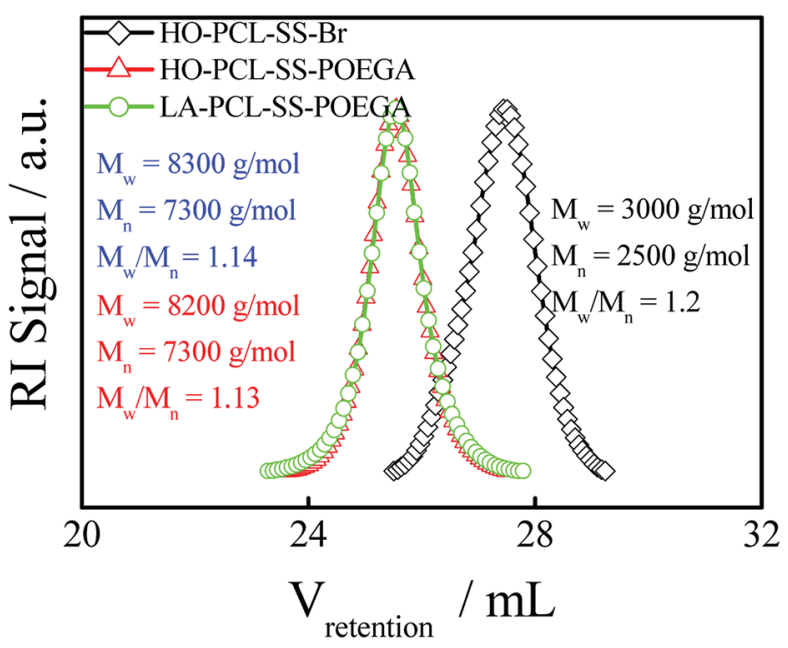

Fig. 2 GPC chromatograms (in THF) of $\mathrm{HO}-\mathrm{PCL}-\mathrm{SS}-\mathrm{Br}, \mathrm{HO}-\mathrm{PCL}-$ SS-POEGA, and LA-PCL-SS-POEGA. The concentration of these polymers was $\sim 5 \mathrm{mg} \mathrm{mL}^{-1}$. 

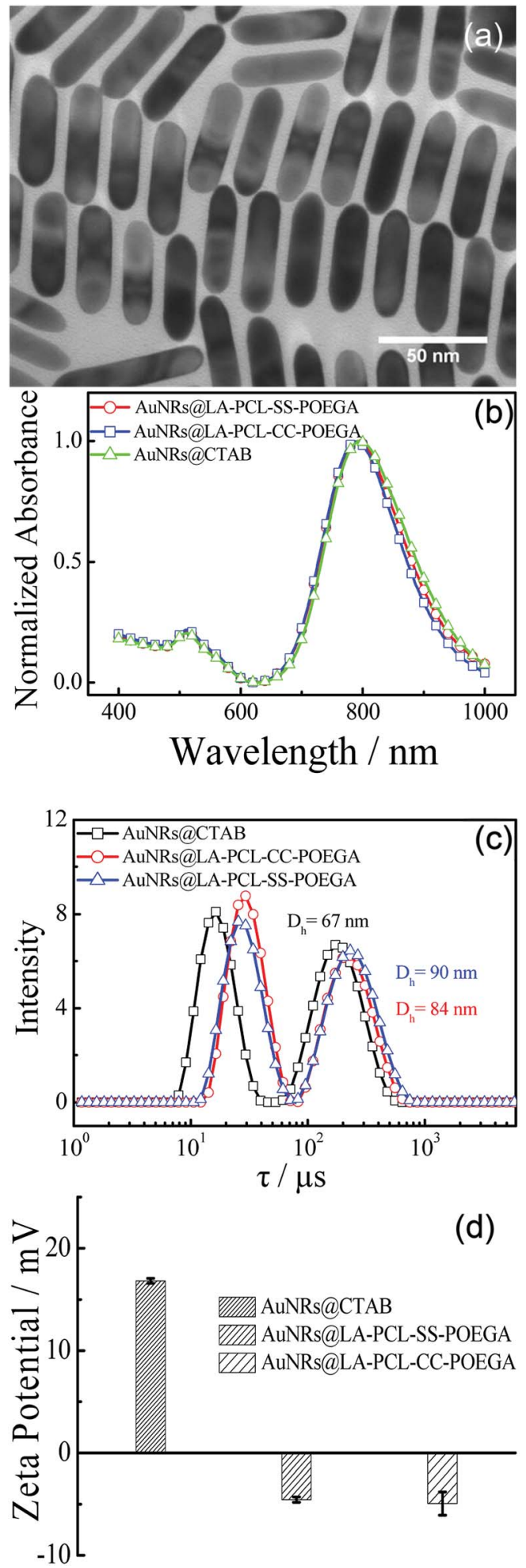

Fig. 3 (a) TEM image of AuNRs $A C T A B$ in an aqueous solution. (b) UV/ vis absorption spectra of AuNRs@CTAB and AuNRs@LA-PCL-RPOEGA dispersed in water. (c) Distribution of relaxation time obtained from DLS measurement for AuNRs@CTAB and AuNRs@LA-PCL-RPOEGA in water. (d) Zeta potentials of AuNRs@CTAB and AuNRs@LA$\mathrm{PCL}-\mathrm{R}-\mathrm{POEGA}$ dispersed in $10 \mathrm{mM}$ phosphate buffer $(\mathrm{pH}=7.4)$ solution. attributed to translational diffusion. The average hydrodynamic diameter of AuNRs@CTAB is $67 \mathrm{~nm}$ obtained from the translational diffusion coefficient. ${ }^{50,51}$ The diameter of AuNRs@CTAB measured by DLS is a little longer than that detected by TEM due to the CTAB bilayer absorbed on the surface of AuNRs. ${ }^{51}$ As shown in the normalized UV/vis absorption spectra [Fig. 3(b)], AuNRs have a strong absorption peak at approximately $802 \mathrm{~nm}$, which is located in the therapeutic window, since biological tissue and water have a lower absorption at $650-900 \mathrm{~nm}^{52}$ According to the absorbance of the longitudinal absorption at $802 \mathrm{~nm}$, the concentration of AuNRs can be determined with a molar extinction coefficient of $4.4 \pm 0.5 \times 10^{9} \mathrm{~L}$ $\mathrm{mol}^{-1} \mathrm{~cm}^{-1}{ }^{33,54}$ Meanwhile, the absorption shape of AuNRs@LA-PCL-R-POEGA is consistent with AuNRs@CTAB, suggesting the monodispersity of nanoparticles after modification.

AuNRs@ LA-PCL-R-POEGA were prepared by forming Au-S bonds between LA and AuNRs according to the method reported by Zhong and coworkers with some modifications. ${ }^{36}$ In the current method, the nanoparticles were washed with DMSO and centrifuged to remove excessive polymers that have not combined with AuNRs. As shown in Fig. 3(c), the relaxation time of translational diffusion for AuNRs@LA-PCL-R-POEGA is longer than that for AuNRs@CTAB. The average hydrodynamic diameters of AuNRs@LA-PCL-R-POEGA calculated from the relaxation time of translational diffusion [Fig. 3(c)] are larger than those of AuNRs@CTAB, with an average diameter of about $87 \pm 3 \mathrm{~nm}$. Since the amphiphilic polymer chains are much longer than the bilayer of CTAB absorbed on AuNRs, the average diameter becomes larger after the copolymer replaced CTAB on the AuNRs. However, a change in the particle size of AuNRs@LA-PCL-RPOEGA cannot be observed from the TEM images due to the low electron density and collapse of the polymer chain after drying. Moreover, the zeta potentials of AuNRs@LA-PCL-R-POEGA in $10 \mathrm{mM}$ PB solution at $\mathrm{pH}=7.4$ are $-4.5 \pm 1 \mathrm{mV}$ [Fig. 3(d)], but the zeta potentials of AuNRs@CTAB in the same medium are $+16.8 \pm$ $1 \mathrm{mV}$ due to the presence of CTAB molecules with positive charge. In addition, Fig. $\mathrm{S} 9 \dagger$ shows that AuNRs@LA-PCL-R-POEGA exhibit good stability and can be well dispersed in organic solvents such as THF and DMSO, while AuNRs@CTAB aggregate or even precipitate in organic solvents. All these results suggest that our copolymers have been successfully grafted onto AuNRs.

\section{Stability of AuNRs@LA-PCL-R-POEGA nanoparticles}

We probed the stabilities of AuNRs@LA-PCL-R-POEGA under different conditions, including PBS, cell culture media, high concentration of sodium chloride solution, and reducing environments. Fig. S10 $\dagger$ shows that the UV/vis absorption peak positions and shapes of AuNRs@LA-PCL-R-POEGA remain constant under all non-reducing environments (a). Meanwhile, the average hydrodynamic diameter of AuNRs@LA-PCL-RPOEGA shown in Fig. S11 $\uparrow$ is essentially constant with low dispersity at $37{ }^{\circ} \mathrm{C}$ in DMEM, containing $10 \%$ FBS, $1 \%$ sodium pyruvate, and $1 \%$ penicillin-streptomycin, which indicates that AuNRs@LA-PCL-R-POEGA could be stable for biological applications. Furthermore, the DTT competition test was used to explore the difference between the stability of AuNRs@LA- 
PCL-SS-POEGA and AuNRs@LA-PCL-CC-POEGA under the reduction condition. ${ }^{45}$ The UV/vis spectra of AuNRs capped with LA-PCL-R-POEGA in an aqueous solution containing $150 \mathrm{mM}$ DTT and $400 \mathrm{mM} \mathrm{NaCl}$ were collected. As shown in Fig. 4(b), AuNRs@LA-PCL-CC-POEGA exhibit fantastic colloidal stability without aggregation after $12 \mathrm{~h}$. The steric hindrance of the amphiphilic polymer grafted on AuNRs prevent the aggregation of AuNRs. In contrast, obvious aggregation was observed for AuNRs@LA-PCL-SS-POEGA at $90 \mathrm{~min}$ after mixing with the DTT solution, which is attributed to the disulfide bond cleavage, as shown in Fig. 4(a). The hydrophilic POEGA blocks depart from the AuNRs surface after this cleavage in the backbone; then, the nanoparticles become more hydrophobic and the steric hindrance of the copolymer decreases. The main difference between AuNRs@LA-PCL-SS-POEGA and the control group is the disulfide bond among the copolymer chain, resulting in the aggregation of AuNRs@LA-PCL-SS-POEGA under the reduction condition.

\section{Photothermal effect of AuNRs@LA-PCL-R-POEGA under NIR irradiation}

AuNRs have shown to be a promising photothermal material owing to their high photothermal conversion efficiency. ${ }^{55,56}$ In order to evaluate the photothermal efficiency of AuNRs, we
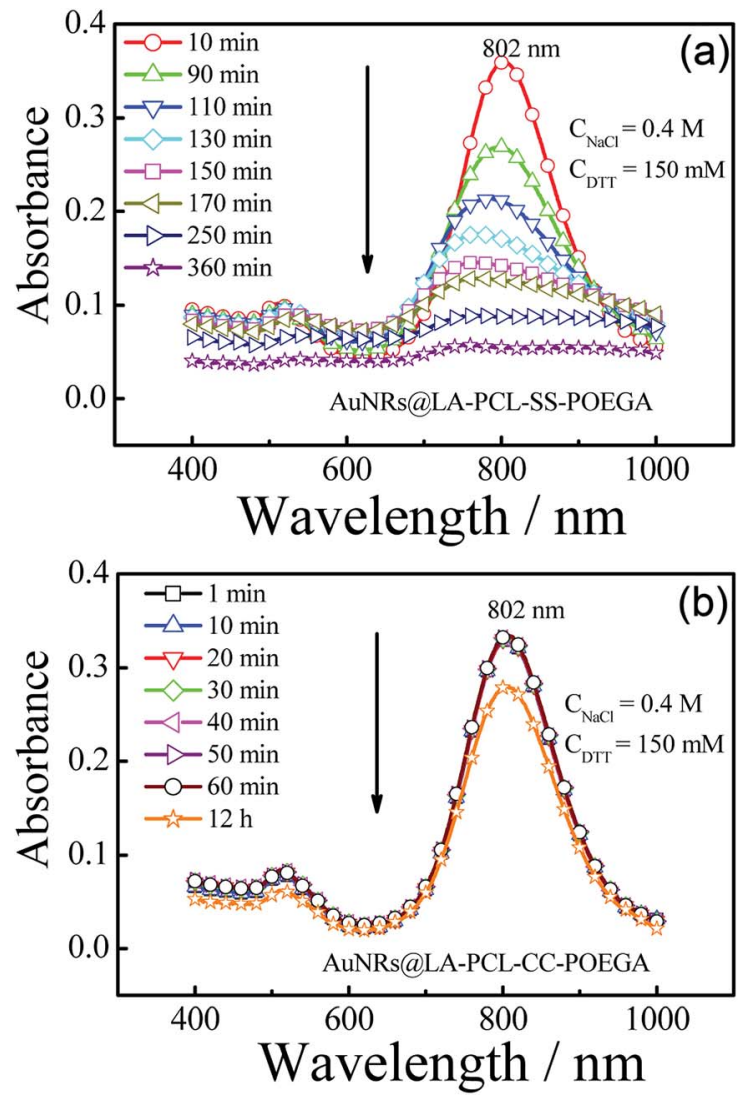

Fig. 4 Time-dependent absorption spectra of (a) AuNRs(aLA-PCLSS-POEGA and (b) AuNRs@LA-PCL-CC-POEGA aqueous solutions containing $150 \mathrm{mM} \mathrm{DTT}$ and $400 \mathrm{mM} \mathrm{NaCl}$ with an initial absorbance $\approx 0.3-0.4$. tested the temperature changes of AuNRs@CTAB and AuNRs@LA-PCL-R-POEGA in aqueous solutions under $808 \mathrm{~nm}$ laser irradiation with different concentrations. Fig. 5(a) shows the rapid temperature changes $\left(\sim 10{ }^{\circ} \mathrm{C}\right)$ within 5 min for AuNRs@LA-PCL-R-POEGA, which is similar for AuNRs@CTAB at the same concentration of $0.1 \mathrm{mg} \mathrm{mL}^{-1}$; as a control, water exhibits almost no change. Furthermore, the dependence of photothermal conversion efficiency on the concentration of AuNRs@LA-PCL-SS-POEGA is also shown in Fig. 5(b). These results reveal that AuNRs modified with LA-PCL-R-POEGA exhibit good photothermal conversion efficiency.

\section{Cell viability and cellular uptake of AuNRs@LA-PCL-R- POEGA}

Fig. 6 shows that AuNRs@CTAB have obvious cytotoxicity on Hela cells before modification with LA-PCL-R-POEGA owing to the presence of CTAB, which is consistent with the results reported in previous studies. ${ }^{25,45}$ Therefore, it is necessary to modify the AuNRs' surfaces with biocompatible materials to improve the consequent biocompatibility. In our work, we capped AuNRs with the biocompatible amphiphilic polymer LA-PCL-R-POEGA, which can simultaneously work as a drug carrier. The cell viability of AuNRs@LA-PCL-R-POEGA
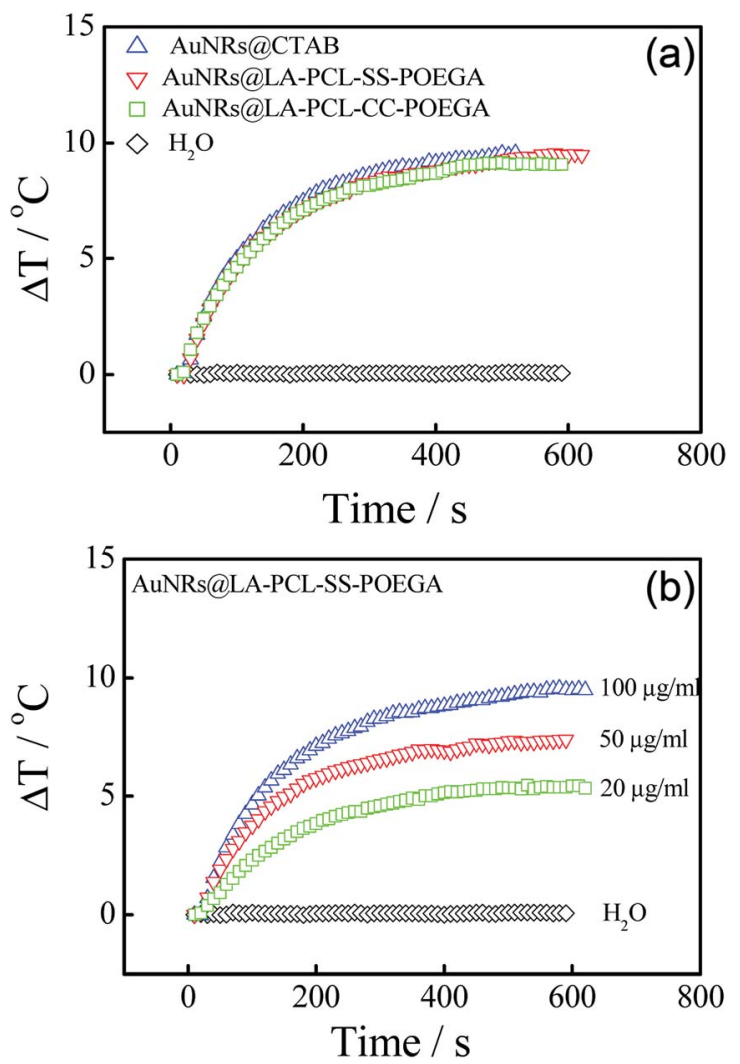

Fig. 5 (a) Photothermal heating curves of water, AuNRs@CTAB, and AuNRs@LA-PCL-R-POEGA irradiated by an $808 \mathrm{~nm}$ laser at a power density of $200 \mathrm{~mW} \mathrm{~cm}^{-2}$ for $10 \mathrm{~min}$. The concentration of AuNRs was $100 \mu \mathrm{g} \mathrm{mL}{ }^{-1}$. (b) Concentration-dependent heating profiles of an aqueous suspension of AuNRs@LA-PCL-SS-POEGA after exposure to $808 \mathrm{~nm}$ NIR laser irradiation $\left(200 \mathrm{~mW} \mathrm{~cm}^{-2}\right)$ for $10 \mathrm{~min}$. 

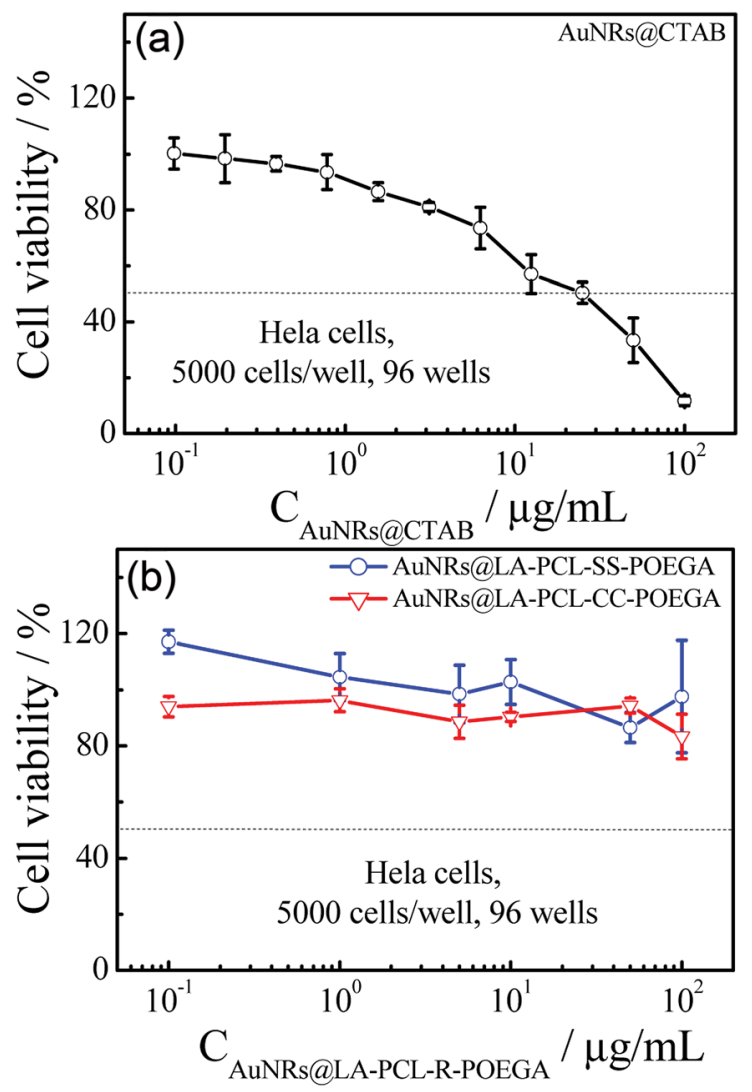

Fig. 6 Cell viability of Hela cells after incubation with (a) AuNRs@CTAB and (b) AuNRs@LA-PCL-R-POEGA at different concentrations for $24 \mathrm{~h}$ was assessed by the standard MTT assay. Error bars represent the mean $\pm \operatorname{SD}(n=6)$.

remained greater than $85 \%$ even at high concentrations of 100 $\mu \mathrm{g} \mathrm{mL}^{-1}$ for Hela cells. The results confirm that the modification with LA-PCL-R-POEGA successfully reduces the cytotoxicity of AuNRs.

The amount of AuNRs internalized within Hela cells was detected by ICP-MS measurements. The concentration of Au ions was measured by ICP-MS after digesting in aqua regia. The

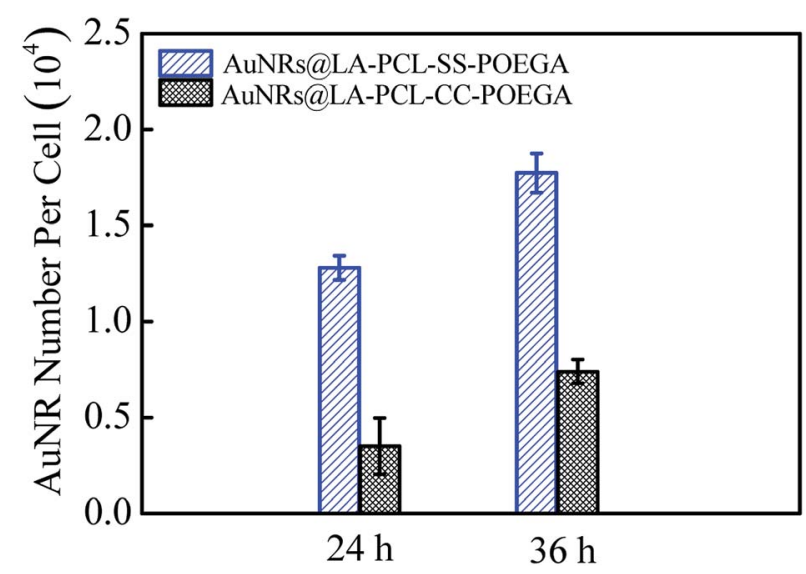

Fig. 7 Internalized number of AuNRs per cell after incubation with AuNRs@LA-PCL-SS-POEGA or AuNRs@LA-PCL-CC-POEGA at 75 $\mu \mathrm{g} \mathrm{mL}{ }^{-1}$ for $24 \mathrm{~h}$ or $36 \mathrm{~h}$. Error bars represent the mean $\pm \mathrm{SD}(n=3)$. number of AuNRs per cell (Fig. 7) was calculated according to the quality of a single AuNR (the volume was obtained from TEM images) and the number of cells in each well. The result shows that the cellular uptake of AuNRs is greatly improved by introducing a disulfide linkage between the PCL and POEGA blocks. The amount of cellular uptake for AuNRs@LA-PCL-SS-POEGA coated with polymers containing disulfide linkage was 2-3 times higher than that of AuNRs@LA-PCL-CC-POEGA after being incubated for $24 \mathrm{~h}$ or $36 \mathrm{~h}$. Accurately, the internalized number per cell of AuNRs@LA-PCL-SS-POEGA is $12800 \pm 640$ and $17700 \pm 1030$ after being incubated for $24 \mathrm{~h}$ and $36 \mathrm{~h}$, respectively. However, the cellular uptake number per cell of AuNRs@LA-PCL-CC-POEGA is $3500 \pm 1500$ and $7400 \pm 610$ after being incubated for $24 \mathrm{~h}$ and $36 \mathrm{~h}$, respectively. It might be related to the poor stability of AuNRs@LA-PCL-SS-POEGA under the reducing condition in tumor cells. AuNRs@LA-PCL-SS-POEGA aggregate obviously due to the cleavage of disulfide bonds under the high concentration of DTT, as shown in Fig. 4. We speculated that AuNRs@LA-PCL-SSPOEGA might aggregate as the disulfide bond can be cleaved by the high concentration of GSH in tumor cells, leading to the aggregation of AuNRs. The aggregates formed in tumor cells are not easily excluded from cells, so the uptake of AuNRs@LA-PCLSS-POEGA nanoparticles was enhanced.

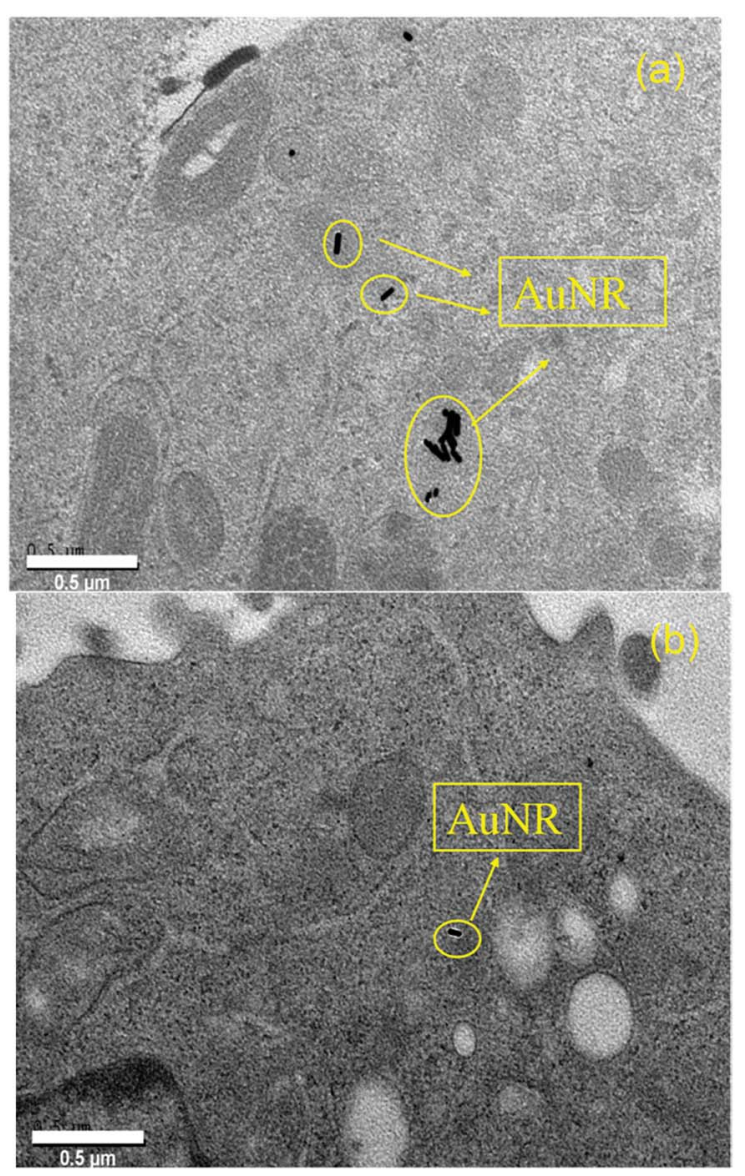

Fig. 8 Location and morphology of AuNRs accumulated in the cells after incubation with (a) AuNRsaLA-PCL-SS-POEGA at $75 \mu \mathrm{g} \mathrm{mL}^{-1}$ and (b) AuNRsaLA-PCL-CC-POEGA at the same concentration for $36 \mathrm{~h}$. Scale bar is $0.5 \mu \mathrm{m}$. 
To further identify the AuNRs@LA-PCL-R-POEGA internalized by the cells, we observed the morphology and location of the intracellular AuNRs with TEM, as shown in Fig. 8. According to the TEM images of the cells treated with AuNRs@LA-PCLSS-POEGA, we found that certain AuNRs formed aggregates in cells and were located in the cytoplasm. However, fewer AuNRs and aggregates were observed in cells from the TEM images after cultivating with AuNRs@LA-PCL-CC-POEGA. Therefore, AuNRs@LA-PCL-SS-POEGA nanoparticles might tend to aggregate after entering into the Hela cells as compared with AuNRs@LA-PCL-CC-POEGA. Thus, these results also indicate the reduction-responsive polymers modified with AuNRs might enhance the cellular uptake for tumor cells.

\section{Conclusions}

In this study, we have successfully synthesized reductionresponsive and terminal functionalized amphiphilic polymer LA-PCL-SS-POEGA with good biocompatibility through ROP and ATRP. The copolymer could be used to replace CTAB and conjugate on AuNRs via the formation of $\mathrm{Au}-\mathrm{S}$ bonds to improve the stability and biocompatibility of AuNRs. The stabilities of AuNRs@LA-PCL-R-POEGA were investigated under different conditions. The results reveal that both AuNRs@LA-PCL-SSPOEGA and AuNRs@LA-PCL-CC-POEGA could be stable under non-reducing conditions. However, under a reducing environment containing 150 mM DTT, AuNRs@LA-PCL-SS-POEGA aggregated obviously according to the UV/vis spectrum changes of AuNRs, while the control group remains stable. In addition, the cell viability obtained from the MTT assay shows that the biocompatibility of AuNRs@LA-PCL-R-POEGA is much better than AuNRs@CTAB. Furthermore, the internalization of AuNRs@LA-PCL-R-POEGA in vitro measured by ICP-MS measurement and TEM demonstrate that the reductionresponsive copolymer might enhance the cellular uptake, presumably due to the aggregation of AuNRs@LA-PCL-SSPOEGA under reduction conditions. We believe that these findings will have a significant impact on the application of AuNRs modified with stimuli-responsive polymers.

\section{Conflicts of interest}

There are no conflicts to declare.

\section{Acknowledgements}

We thank Professor Yucai Wang for generously providing NearInfrared laser. The financial support of the National Natural Scientific Foundation of China (NNSFC) Project (21674107) and the Fundamental Research Funds for the Central Universities (WK2340000066) is gratefully acknowledged.

\section{Notes and references}

1 A. Mandal, R. Bisht, I. D. Rupenthal and A. K. Mitra, J. Controlled Release, 2017, 248, 96-116.
2 S. Biswas, P. Kumari, P. M. Lakhani and B. Ghosh, Eur. J. Pharm. Sci., 2016, 83, 184-202.

3 A. Gothwal, I. Khan and U. Gupta, Pharm. Res., 2016, 33, 1839.

4 H. Maeda, H. Nakamura and J. Fang, Adv. Drug Delivery Rev., 2013, 65, 71-79.

5 Y. P. Li, K. Xiao, W. Zhu, W. B. Deng and K. S. Lam, Adv. Drug Delivery Rev., 2014, 66, 58-73.

6 S. Mura, J. Nicolas and P. Couvreur, Nat. Mater., 2013, 12, 991-1003.

7 K. Engin, D. B. Leeper, J. R. Cater, A. J. Thistlethwaite, L. Tupchong and J. D. McFarlane, Int. J. Hyperthermia, 1995, 11, 211-216.

8 E. S. Lee, Z. G. Gao and Y. H. Bae, J. Controlled Release, 2008, 132, 164-170.

9 J. Liu, Y. R. Huang, A. Kumar, A. Tan, S. Jin, A. Mozhi and X. J. Liang, Biotechnol. Adv., 2014, 32, 693-710.

10 M. Stubbs, P. M. J. McSheehy, J. R. Griffiths and C. L. Bashford, Mol. Med. Today, 2000, 6, 15-19.

11 Y. Li, J. J. Li, B. Chen, Q. X. Chen, G. Y. Zhang, S. Y. Liu and Z. S. Ge, Biomacromolecules, 2014, 15, 2914-2923.

12 S. Panja, G. Dey, R. Bharti, K. Kumari, T. K. Maiti, M. Mandal and S. Chattopadhyay, ACS Appl. Mater. Interfaces, 2016, 8, 12063-12074.

13 P. Kuppusamy, H. Q. Li, G. Ilangovan, A. J. Cardounel, J. L. Zweier, K. Yamada, M. C. Krishna and J. B. Mitchell, Cancer Res., 2002, 62, 307-312.

14 F. H. Meng, W. E. Hennink and Z. Y. Zhong, Biomaterials, 2009, 30, 2180-2198.

15 G. Saito, J. A. Swanson and K. D. Lee, Adv. Drug Delivery Rev., 2003, 55, 199-215.

16 Y. F. Wen and J. K. Oh, RSC Adv., 2014, 4, 229-237.

17 K. Rahimian, Y. F. Wen and J. K. Oh, Polymer, 2015, 72, 387394.

18 A. Cunningham, N. R. Ko and J. K. Oh, Colloids Surf., B, 2014, 122, 693-700.

19 W. Chen, P. Zhong, F. H. Meng, R. Cheng, C. Deng, J. Feijen and Z. Y. Zhong, J. Controlled Release, 2013, 169, 171-179.

20 H. L. Sun, B. N. Guo, R. Cheng, F. H. Meng, H. Y. Liu and Z. Y. Zhong, Biomaterials, 2009, 30, 6358-6366.

21 H. L. Sun, B. N. Guo, X. Q. Li, R. Cheng, F. H. Meng, H. Y. Liu and Z. Y. Zhong, Biomacromolecules, 2010, 11, 848-854.

22 J. J. Shi, P. W. Kantoff, R. Wooster and O. C. Farokhzad, Nat. Rev. Cancer, 2017, 17, 20-37.

23 S. Parida, C. Maiti, Y. Rajesh, K. K. Dey, I. Pal, A. Parekh, R. Patra, D. Dhara, P. K. Dutta and M. Mandal, Biochim. Biophys. Acta, Gen. Subj., 2017, 1861, 3039-3052.

24 Z. J. Zhang, J. Wang, X. Nie, T. Wen, Y. L. Ji, X. C. Wu, Y. L. Zhao and C. Y. Chen, J. Am. Chem. Soc., 2014, 136, 7317-7326.

25 Y. Qiu, Y. Liu, L. M. Wang, L. G. Xu, R. Bai, Y. L. Ji, X. C. Wu, Y. L. Zhao, Y. F. Li and C. Y. Chen, Biomaterials, 2010, 31, 7606-7619.

26 X.-M. Zhu, C. H. Fang, H. L. Jia, Y. Huang, C. H. K. Cheng, C.-H. Ko, Z. Y. Chen, J. F. Wang and Y.-X. J. Wang, Nanoscale, 2014, 6, 11462-11472. 
27 L. Vigderman, P. Manna and E. R. Zubarev, Angew. Chem., Int. Ed., 2012, 51, 636-641.

28 Z. B. Li, S. Y. Tang, B. K. Wang, Y. Li, H. Huang, H. Y. Wang, P. H. Li, C. Z. Li, P. K. Chu and X.-F. Yu, ACS Biomater. Sci. Eng., 2016, 2, 789-797.

29 Y. Jiang, S. D. Huo, T. Mizuhara, R. Das, Y. W. Lee, S. Hou, D. F. Moyano, B. Duncan, X. J. Liang and V. M. Rotello, ACS Nano, 2015, 9, 9986-9993.

30 C. Grabinski, N. Schaeublin, A. Wijaya, H. D'Couto, S. H. Baxamusa, K. Hamad-Schifferli and S. M. Hussain, ACS Nano, 2011, 5, 2870-2879.

31 T. B. Huff, M. N. Hansen, Y. Zhao, J. X. Cheng and A. Wei, Langmuir, 2007, 23, 1596-1599.

32 T. Mizuhara, K. Saha, D. F. Moyano, C. S. Kim, B. Yan, Y.-K. Kim and V. M. Rotello, Angew. Chem., Int. Ed., 2015, 54, 6567-6570.

33 A. M. Alkilany, P. K. Nagaria, C. R. Hexel, T. J. Shaw, C. J. Murphy and M. D. Wyatt, Small, 2009, 5, 701-708.

34 E. Oh, J. B. Delehanty, K. E. Sapsford, K. Susumu, R. Goswami, J. B. Blanco-Canosa, P. E. Dawson, J. Granek, M. Shoff, Q. Zhang, P. L. Goering, A. Huston and I. L. Medintz, ACS Nano, 2011, 5, 6434-6448.

35 T. S. Hauck, A. A. Ghazani and W. C. W. Chan, Small, 2008, 4, 153-159.

36 Y. N. Zhong, C. Wang, L. Cheng, F. H. Meng, Z. Y. Zhong and Z. Liu, Biomacromolecules, 2013, 14, 2411-2419.

37 J. Liu, C. Detrembleur, B. Grignard, M.-C. De Pauw-Gillet, S. Mornet, M. Treguer-Delapierre, Y. Petit, C. Jérôme and E. Duguet, Chem.-Asian J., 2014, 9, 275-288.

38 Z. G. Tang, J. T. Callaghan and J. A. Hunt, Biomaterials, 2005, 26, 6618-6624.

39 K. Rezwan, Q. Z. Chen, J. J. Blaker and A. R. Boccaccini, Biomaterials, 2006, 27, 3413-3431.
40 L. W. Li, X. Wang, J. X. Yang, X. D. Ye and C. Wu, Macromolecules, 2014, 47, 650-658.

41 Z. Q. Cao, H. Wu, J. Dong and G. J. Wang, Macromolecules, 2014, 47, 8777-8783.

42 J. X. Yang, L. W. Li, Z. Y. Jing, X. D. Ye and C. Wu, Macromolecules, 2014, 47, 8437-8445.

43 H. Y. Fan, Y. X. Li, J. X. Yang and X. D. Ye, J. Phys. Chem. B, 2017, 121, 9708-9717.

44 B. Nikoobakht and M. A. El-Sayed, Chem. Mater., 2003, 15, 1957-1962.

45 X. S. Liu, N. Huang, H. Li, H. B. Wang, Q. Jin and J. Ji, ACS Appl. Mater. Interfaces, 2014, 6, 5657-5668.

46 M. H. Stewart, K. Susumu, B. C. Mei, I. L. Medintz, J. B. Delehanty, J. B. Blanco-Canosa, P. E. Dawson and H. Mattoussi, J. Am. Chem. Soc., 2010, 132, 9804-9813.

47 C. R. Martin, Science, 1994, 266, 1961-1966.

48 Y. Y. Yu, S. S. Chang, C. L. Lee and C. R. C. Wang, J. Phys. Chem. B, 1997, 101, 6661-6664.

49 Q. S. Wei, J. Ji and J. C. Shen, J. Nanosci. Nanotechnol., 2008, 8, 5708-5714.

50 M. Glidden and M. Muschol, J. Phys. Chem. C, 2012, 116, 8128-8137.

51 J. Rodríguez-Fernández, J. Pérez-Juste, L. M. Liz-Marzán and P. R. Lang, J. Phys. Chem. C, 2007, 111, 5020-5025.

52 R. Weissleder, Nat. Biotechnol., 2001, 19, 316-317.

53 H. W. Liao and J. H. Hafner, Chem. Mater., 2005, 17, 46364641.

54 C. J. Orendorff and C. J. Murphy, J. Phys. Chem. B, 2006, 110, 3990-3994.

55 S. Shen, H. Y. Tang, X. T. Zhang, J. F. Ren, Z. Q. Pang, D. G. Wang, H. L. Gao, Y. Qian, X. G. Jiang and W. L. Yang, Biomaterials, 2013, 34, 3150-3158.

56 R. F. Zhao, X. X. Han, Y. Y. Li, H. Wang, T. J. Ji, Y. L. Zhao and G. J. Nie, ACS Nano, 2017, 11, 8103-8113. 